\title{
Acoustic Measurements for Small Solid Rocket Motors
}

Acoustical Society of America

NOISE - CON 2010

April 19-23, 2010

Magda B. Vargas

All Points Logistics/ESTS Group

R. Jeremy Kenny

Marshall Space Flight Center 


\section{Agenda}

- Overview and Scope

- Small Solid Rocket Motor Parameters

- Test Setup and Microphone Layout

- Instrumentation

- Procedures

- Data Analysis

- Time Histories

- $1 / 3$ Octave bands

- Summary and conclusions 


\section{Overview and scope}

- Models have been developed to predict large solid rocket motor acoustic loads based on the scaling of small solid rocket motors

- MSFC has measured several small solid rocket motors in horizontal and launch configurations to anchor these models

- Solid Rocket Test Motor (SRTM) has ballistics similar to the Reusable Solid Rocket Motor (RSRM) therefore a good choice for acoustic scaling

- Acoustic measurements were collected during the test firing of the Insulation Configuration Extended Length (ICXL) 7,6, and 8 (in firing order) in order to compare to RSRM horizontal firing data

- The scope of this presentation includes:

- Acoustic test procedures and instrumentation implemented during the three SRTM firings

- Data analysis method and general trends observed in the data 


\section{Parameters}

\begin{tabular}{|l|l|l|}
\hline Parameters & ICXL & RSRM \\
\hline Thrust & $50,000 \mathrm{lbf}$ & $300,000 \mathrm{lbf}$ \\
\hline Exit Diameter & $0.97 \mathrm{ft}$ & $12 \mathrm{ft}$ \\
\hline
\end{tabular}
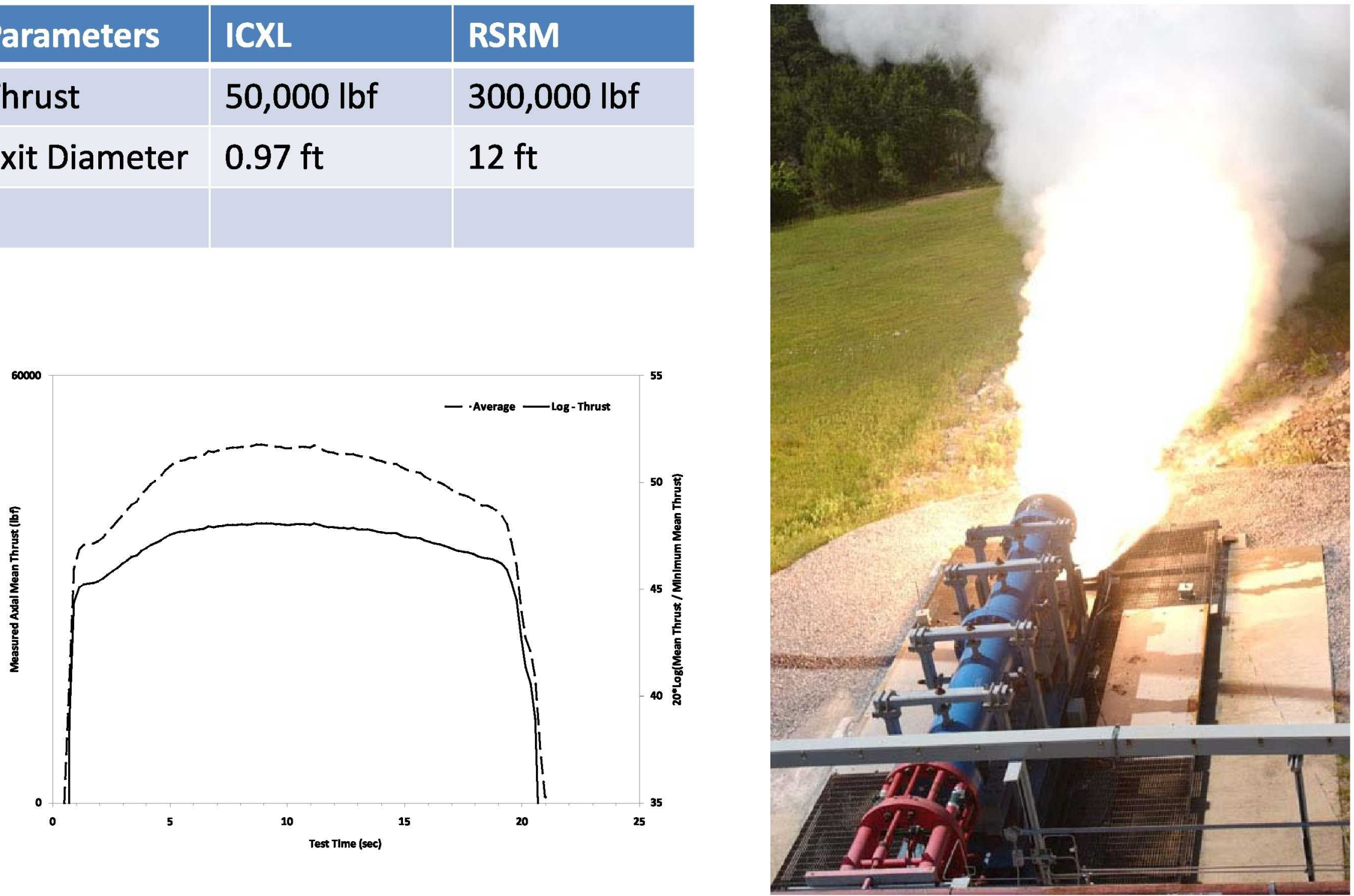


\section{Test Setup}

- Microphone layout based on nozzle diameters for scaling

- Sensors installed on unistrut stands and leveled with the nozzle exit plane

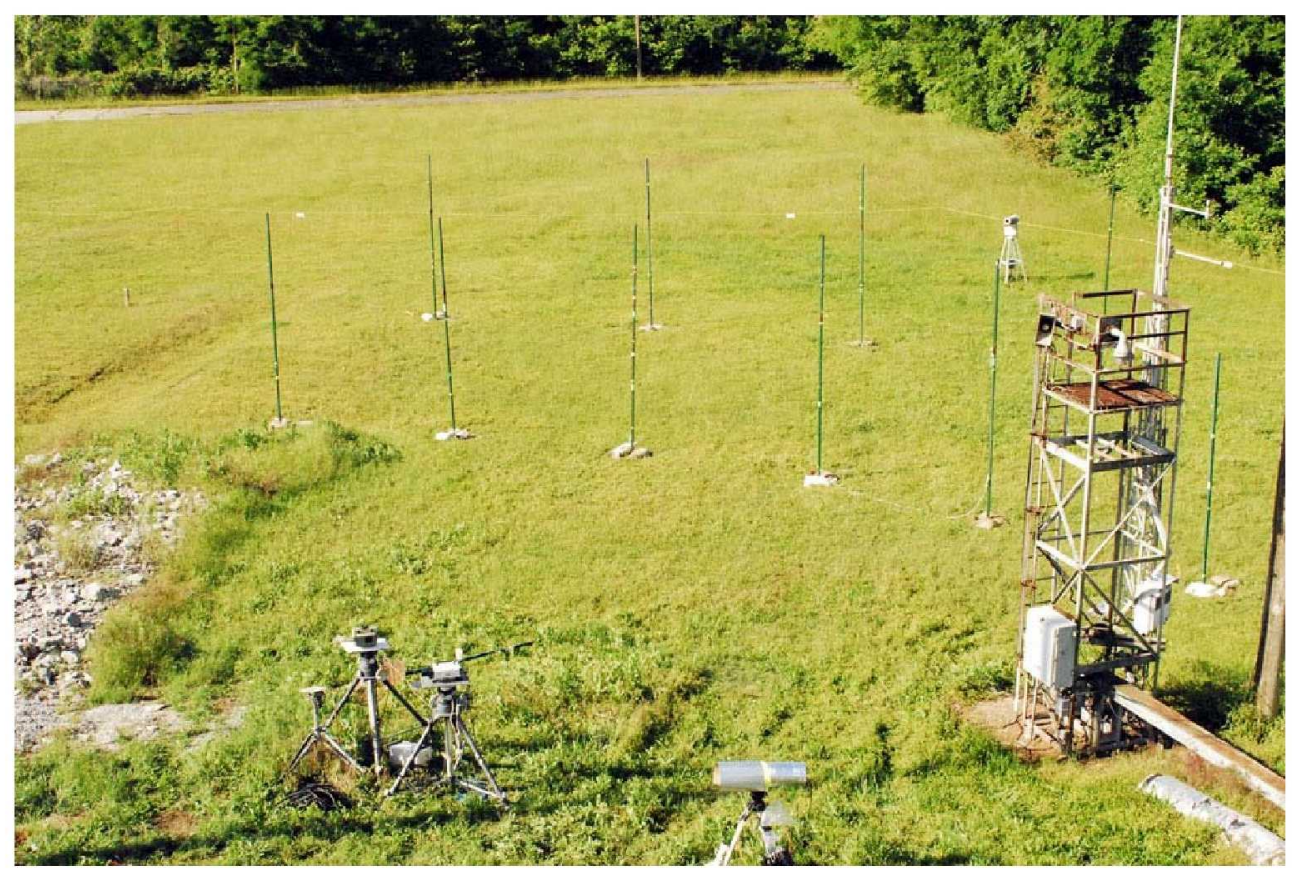

- Uni-struts placed on 80 and 120 ND from the nozzle centerline 


\section{Instrumentation}

- PCB 106B50, 5 psi, $10 \mathrm{kHz}$, quartz microphone

- Several DAQs were used for the tests due to availability

- VXI 1432 ICXL7 and 6

- VXI 1436 ICXL8

- IRIG-B was provided by the test area

- Weather information was collected by the test area

- Microphone location determined using an infrared GPS 


\section{Procedures}

- Pre and Post-test calibration measured using a B\&K pistonphone, $124 \mathrm{~dB}$ at $250 \mathrm{~Hz}$

- System triggered remotely via ethernet using PCAnywhere software

- The system is started approximately 1 second before T-0, IRIG-B can be used to adjust the data to T-0 


\section{Data Analysis}

- Data analysis performed using PCSignal

- Sample rate varied from test to test due to different DAQ and channel numbers

- Time: 8 second interval with $80 \%$ overlap

- Frequency: 5 second interval, $1.3 \mathrm{~Hz}$ bandwidth with $80 \%$ overlap

- The processing block size was selected according to the sample rate to best match the parameters

- The time interval was selected to encompass the maximum thrust time period 


\section{Time Histories}

80 Nozzle Diameters @ 30

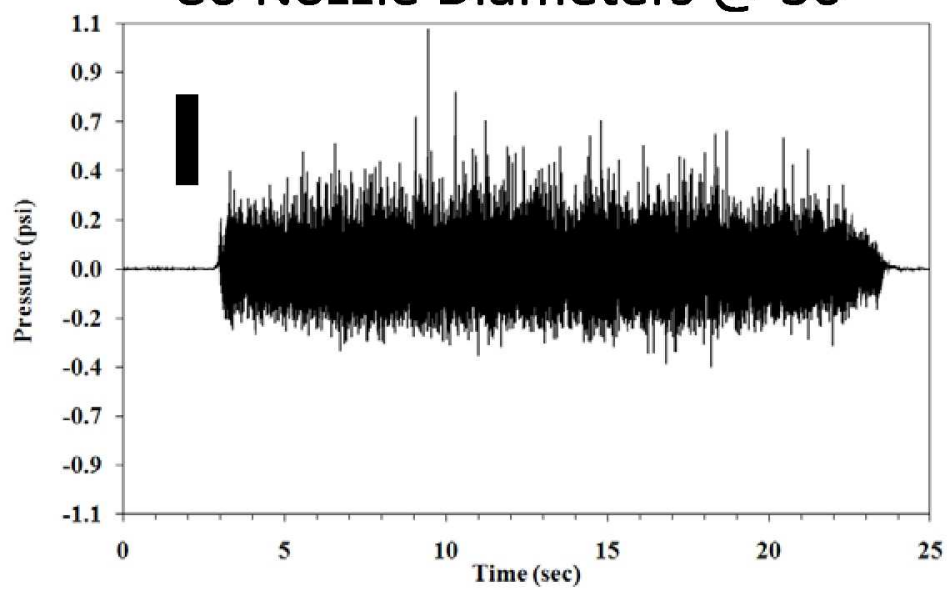

120 Nozzle Diameters @ 30

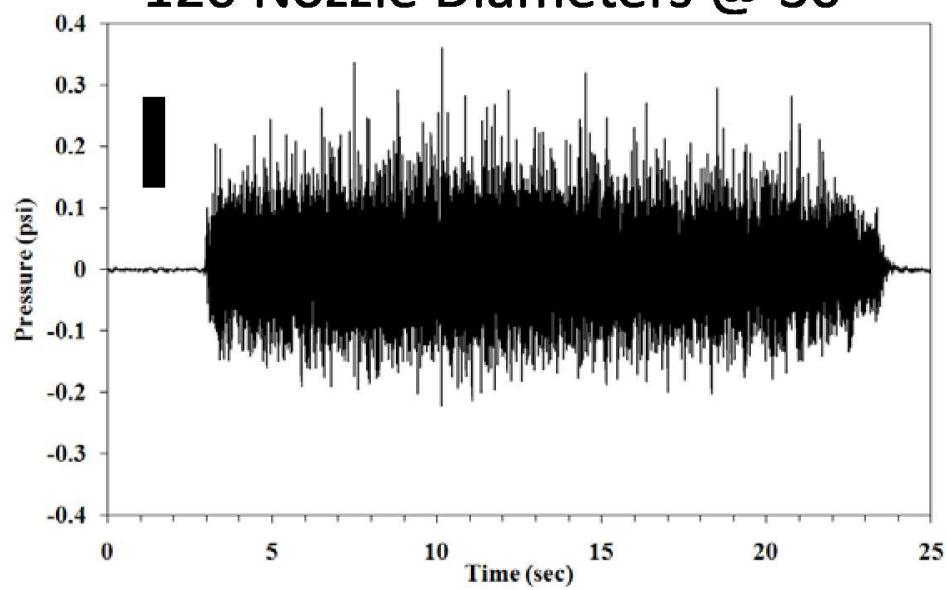

- Time histories show positively skewed data

- Similar behavior has been observed in RSRM data
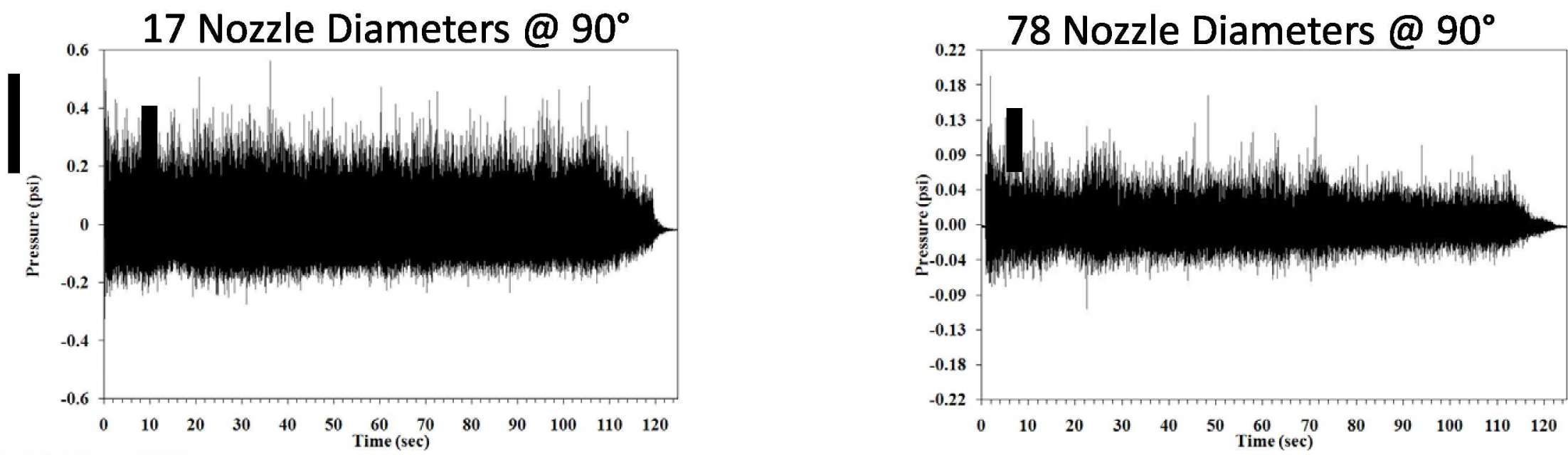


\section{Overall Sound Pressure Level}

\section{ICXL-7}

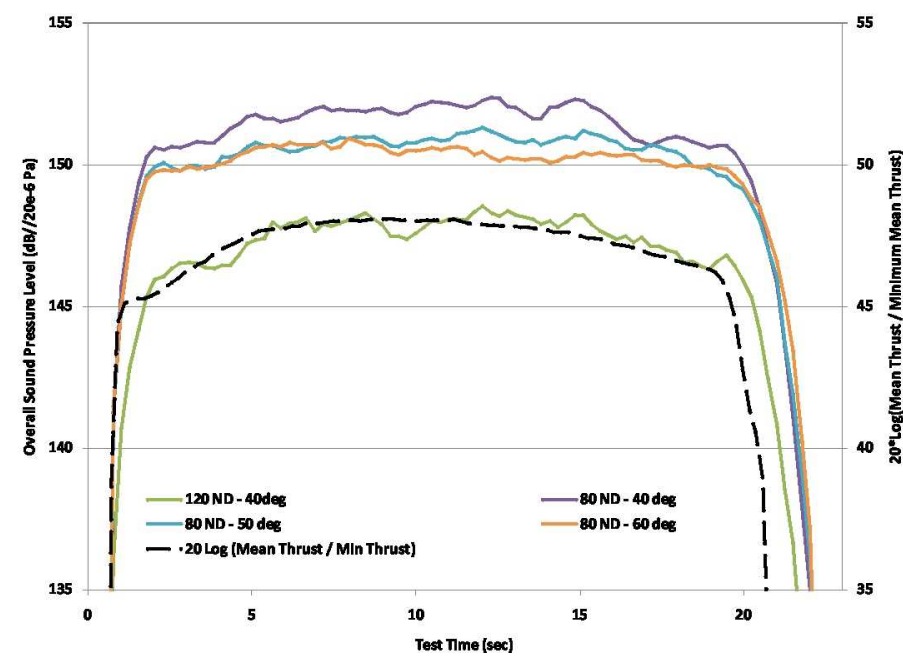

ICXL-6

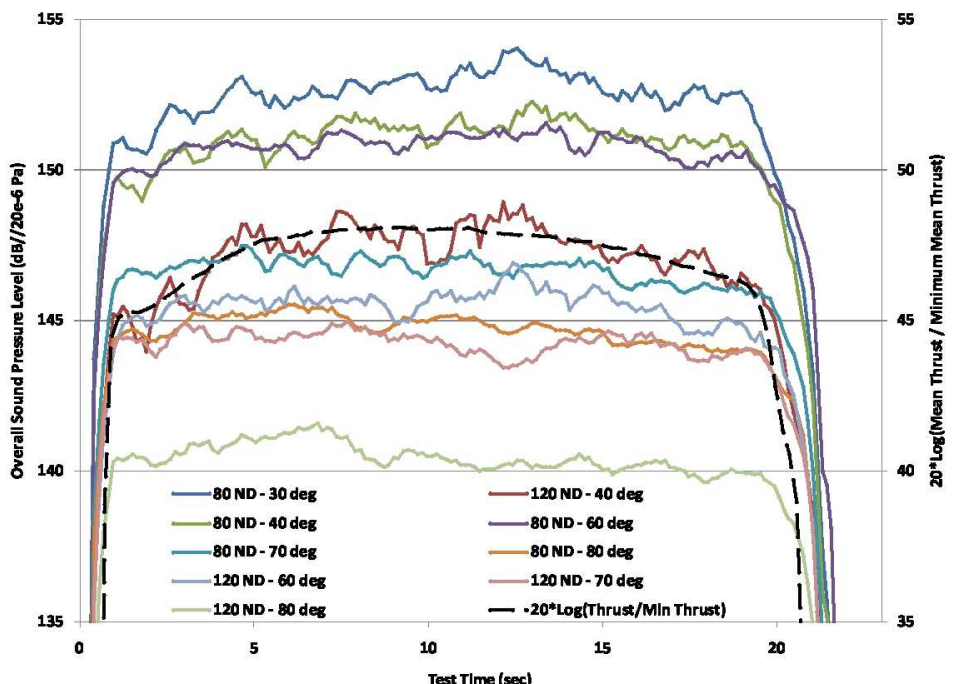

ICXL-8

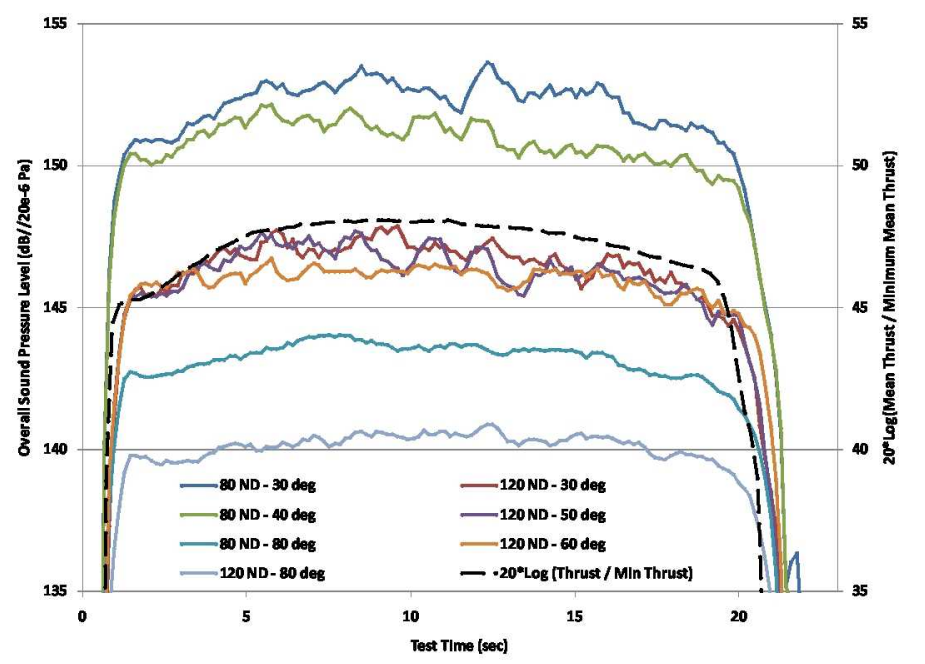

- Acoustic data follows the thrust max

- $3 \mathrm{~dB}$ reduction with $50 \%$ distance increase 


\section{1/3 Octave Bands}
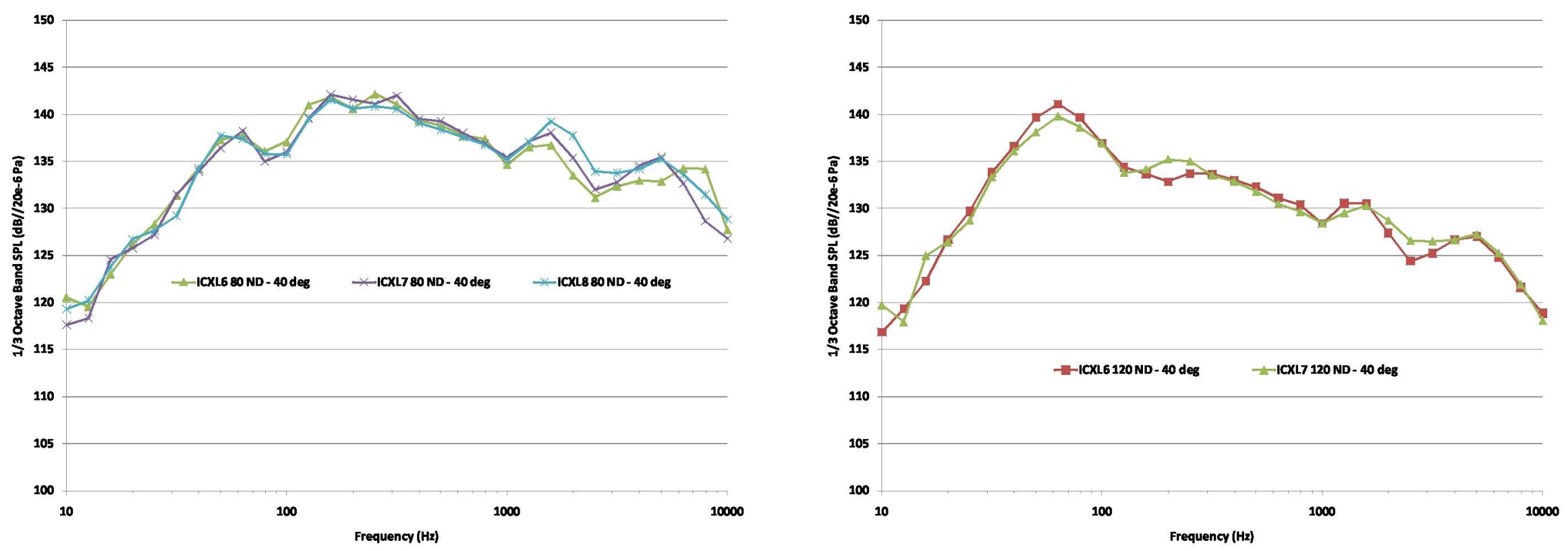

- $1 / 3$ Octaves shows repeatability of the measurements from test to test 


\section{Summary and future work}

- Measured acoustic data shows repeatability and trend similar to the ones shown in previous static firings

- One more SRTM will be measured in May

- Data will be collected to make the required corrections 